\title{
Outcomes in patients with early stage uterine clear cell carcinoma treated with chemotherapy and radiotherapy: A systematic review and meta- analysis
}

\section{Xia Yin ( $\nabla$ yinxia2@aliyun.com )}

Shanghai Jiao Tong University School of Medicine Affiliated Renji Hospital https://orcid.org/00000003-4901-7068

Jie Cheng

Shanghai Jiao Tong University School of Medicine Affiliated Renji Hospital

\section{Yi Zhang}

Shanghai Jiao Tong University School of Medicine Affiliated Renji Hospital

Chee Wai Chua

Shanghai Jiao Tong University School of Medicine Affiliated Renji Hospital

Cheng Zhou

Southern Medical University Nanfang Hospital

\section{Guanglei Zhuang}

Shanghai Jiao Tong University School of Medicine Affiliated Renji Hospital

\section{Wen Di}

Shanghai Jiao Tong University School of Medicine Affiliated Renji Hospital

\section{Daniel J. Corsi}

Ottawa Hospital Research Institute

\section{Research article}

Keywords: uterus clear cell cancer, adjuvant therapy, chemotherapy, radiotherapy, overall survival, metaanalysis

Posted Date: January 9th, 2020

DOI: https://doi.org/10.21203/rs.2.20417/v1

License: (9) This work is licensed under a Creative Commons Attribution 4.0 International License. Read Full License 


\section{Abstract}

Background : Uterine clear cell carcinoma (UCCC) is a rare histological type of endometrial cancer with poor prognosis and high risk of tumor relapse. Although adjuvant chemotherapy (CT) and/or radiotherapy (RT) are often recommended for early stage UCCC patients, the effectiveness of these treatment strategies remains unclear.

Methods : Systematic review and meta-analysis were applied to evaluate treatment-related outcomes of stage I-II UCCC patients. Search strategy was applied using electronic databases until June 1st, 2019. Inclusion criteria were retrospective, observational and prospective studies that reported outcome of UCCC patients receiving adjuvant therapy. Clinical endpoints like overall survival (OS) and progressionfree survival (PFS) were evaluated. Data were extracted by two independent reviewers and a metaanalysis was performed.

Results : 13 articles with a total of 3967 patients were analyzed. Overall, adjuvant CT after surgery could improve 5 year-OS significantly compared to patients without CT (odds ratio $0.75,95 \%$ confidence interval [Cl] 0.58-0.96; $\mathrm{p}=0.02$ ). In comparison, RT could also improve OS in UCCC patients of early stage (odds ratio $0.58,95 \% \mathrm{Cl} 0.44-0.77 ; p=0.0002$ ) compared to the patients without RT, especially in US and Europe patients. Lastly, when comparing the patients undergoing both CT and RT with those receiving CT or RT alone, no further improvement in OS was observed (odds ratio 1.12, 95\% $\mathrm{Cl} 0.63-1.99 ; \mathrm{P}=0.70$ ).

Conclusions : Either CT or RT after surgery could improve the OS of early stage of UCCC patients. However, combinatorial CT and RT treatment did not improve the OS compared with CT or RT treatment alone.

\section{Background}

Uterine clear cell carcinoma (UCCC), which accounts for $1-5 \%$ of endometrial cancers, is a highly aggressive cancer subtype that is frequently associated to poor prognosis and high tumor recurrence (1). Notably, up to $30 \%$ of UCCC patients demonstrated pelvic recurrence, whereas distant recurrence was found in up to $60 \%$ of these patients. Moreover, the 5-year overall survival (OS) for UCCC was approximately $60 \%$ compared to over $80 \%$ OS for other endometrial cancers (2).

Chemotherapy (CT) and/or radiotherapy (RT) are used as adjuvant treatment after complete surgery of endometrial cancer in order to improve patients' prognosis. Notably, as more aggressive histologic variants of malignant tumor, National Comprehensive Cancer Network (NCCN) Guidelines suggested different treatment strategies treated for UCCC and endometrioid adenocarcinoma. Up to present, there is no consensus concerning the specific treatment, particularly for stage I-II UCCC patients after primary treatment. The preferred adjuvant therapy is systemic therapy with vaginal brachytherapy, but the patients could also be treated by vaginal brachytherapy with or without external beam radiation therapy (EBRT) as recommended in NCCN guideline. Moreover, close monitoring prior to further treatment in patients of IA stage was also suggested. Recently, pooled analysis showed that application of adjuvant 
CT and RT in stage IA endometrial cancer with serous, clear cell or mixed histology was associated with better PFS compared to those from the observation group. Observation might benefit the patients only when there was adequate surgical staging (3). For patients with stage IB and II disease, different adjuvant therapies were recommended in the NCCN guidelines. Taken together, the optimal adjuvant therapy for early UCCC remains unclear.

There is not enough data on the use of chemotherapy in early-stage clear cell cancers, although some clinical trials from Gynecologic Oncology Group (GOG) have investigated the effect of adjuvant therapy on UCCC (4). Furthermore, most retrospective studies often categorize both serous and clear cell subtypes as type II endometrial cancer, assuming that their clinical outcomes are same. Consequently, none of the individual studies could provide sufficient power for precise evaluation of the effect of adjuvant therapy in UCCC patients.

To our knowledge, the prognostic index of adjuvant therapy including progress free survival (PFS), disease free survival (DFS) or overall survival (OS) has not been systematically evaluated in early stage UCCC patients combining the data from all eligible previous studies. Therefore, in this meta-analysis, we aim to summarize and compare the impact of different adjuvant therapy regimens on prognostic value of early stage UCCC, thus providing practical implications for these disease.

\section{Methods}

To conduct systematic review and meta-analysis, electronic searches from Web of Science, PubMed and Medline were performed independently by two reviewers (X.Y. and J.C.) to identify all relevant studies that evaluated the efficacy of adjuvant therapy in early stage UCCC. The selection strategy for the database search is: ("adjuvant therapy" or "systemic therapy" or "chemotherapy" or "radiotherapy" AND "Uterine Clear Cell Carcinoma" or "UCCC" or "Endometrial Clear Cell Carcinoma").

The search was concluded on June 1st, 2019, and was limited to publications written in English. Additional publications that were not identified during the electronic searches were selected manually. Publications in the forms of retrospective, observational and prospective randomized controlled trials were included, while publications like letters, case studies, or reviews were excluded. In addition, studies with unclear description of data on the outcomes of interests were also excluded from the analyses. Authors of identified studies were contacted for clarification on methods and outcomes when necessary. Disagreements between the two reviewers were resolved through discussion. All extracted data from the selected studies was arranged using a standard PRISMA data extraction form.

General characteristics of the extracted data included author names, year of publication, country, number and age of patients, different type of therapies and cases of different events based on 5-year OS and PFS. To ensure the completeness and accuracy of the extracted data, two reviewers (X.Y. and J.C.) extracted the data from the identified studies independently and then cross-checked their results. When discrepancies arose, the final decision was made through discussion. If the relevant data were not clear in 
a particular study, the corresponding author of the publication was contacted by email for further clarification.

The risk of bias was assessed by the reviewers in accordance to the Cochrane Handbook for Systematic Reviews of Interventions. The seven domains related to risk of bias that were evaluated for each trial included: (1) details of the randomization method, (2) concealment of treatment allocation, (3) masking of the participants and personnel, (4) blinding of the outcome assessment, (5) incomplete outcome data, (6) selective reporting, and (7) other bias. For each criterion, the risk of bias was rated as low, high, or unclear. Disagreement was resolved through discussion.

Data synthesis was performed using RevMan 5.3 (Cochrane Collaboration, London, UK). Continuous data were presented as mean value and standard deviation, and the weighted mean difference and $95 \%$ confidence interval $(\mathrm{Cl})$ were also calculated. Dichotomous data were expressed as odds ratios (ORs) with $95 \%$ Cls. $p<0.05$ was considered statistically significant. The heterogeneity in outcomes across all the trials was assessed using the $\chi^{2}$ and $I^{2}$ tests. An $I^{2}$ value $>50 \%$ was considered to indicate substantial heterogeneity, which prompted the use of a random-effect model for the subsequent analysis; otherwise, a fixed-effect model was applied. Meta-regression was applied when the heterogeneity was existed. Subgroup analysis was also performed to further meta-analysis when the study number is no smaller than 10. Publication bias was assessed by a funnel plot, in which the sample size was plotted on the $Y$ axis and the pooled OR on the X-axis. The presence of bias was considered when an asymmetrical plot was evidenced, whereas a symmetrical plot suggested no bias in the assessed publication. Begg's test and Egger's regression test for publication bias were calculated by Rstudio 1.2.1335 using package "Metafor".

\section{Results}

\subsection{Eligible studies and their characteristics.}

After initial search of the databases, we identified 59 potentially relevant reports from Pubmed and Medline $(n=27)$ and Web of Science $(n=32)$. After excluding repeated publications, a final 36 articles were examined. 14 articles were eliminated for analyses for the following reasons: (1) the reports were review or abstract $(n=5),(2)$ non-English articles $(n=1),(3)$ the reports were not related to adjuvant therapy in UCCC $(n=8)$. Full-text review were performed on 22 articles and 1 manually inquired articles. After carefully performing data extraction, an addition of 10 articles was removed from the analyses due to insufficient data. In the end, 13 articles were included in this meta-analysis (5-17) (Supplemental Fig. 1).

\subsection{Characteristics of the included studies}

13 articles included consisted 3963 patients in total. The quality assessment and main characteristics of the included studies were summarized in Table 1 and Supplemental Fig. 2 respectively. All studies 
selected were assessed to be in a good quality. The follow-up time of patients was more than 60 months to achieve the 5-year overall survival. 
Table 1

Basic characteristics of included studies.

\begin{tabular}{|c|c|c|c|c|c|}
\hline No & Author & Year & Clincal Trial & Nationality & Median age \\
\hline 1 & $\begin{array}{l}\text { Creasman } \\
\text { et al }\end{array}$ & 2004 & $\begin{array}{l}\text { retrospective of the 25th Annual Report of } \\
\text { FIGO published in } 2001\end{array}$ & Italy & NA \\
\hline 2 & $\begin{array}{l}\text { Thomas et } \\
\text { al }\end{array}$ & 2008 & $\begin{array}{l}\text { A retrospective review was conducted at } 2 \\
\text { major gynecologic cancer centers } \\
\text { between } 1998 \text { to } 2004\end{array}$ & US & 64 \\
\hline 3 & $\begin{array}{l}\text { Rauh-Hain } \\
\text { et al }\end{array}$ & 2009 & $\begin{array}{l}\text { a retrospective review conducted at the } \\
\text { Massachusetts General Hospital and } \\
\text { Brigham and Women's Hospital between } \\
\text { January, } 1996 \text { to January, } 2007\end{array}$ & US & $\begin{array}{l}64 \pm 7 \text { for } \\
\text { adjuvant } \\
\text { therapy } \\
70 \pm 8 \text { for } \\
\text { observation }\end{array}$ \\
\hline 4 & Hsu et al & 2014 & $\begin{array}{l}\text { retrospective TGOG between } 1991 \text { to } \\
2010\end{array}$ & $\begin{array}{l}\text { Chinese } \\
\text { Taiwan }\end{array}$ & $\begin{array}{l}59.9 \pm 10.9 \\
(33-86)\end{array}$ \\
\hline 5 & Ly et al & 2014 & $\begin{array}{l}\text { a retrospective review conducted at the } \\
\text { University of Utah from } 1992 \text { to } 2011\end{array}$ & US & $\begin{array}{l}\text { RT: } \\
68(63.8- \\
69) \\
\text { Not- } \\
\text { RT:66(64.4- } \\
69.8)\end{array}$ \\
\hline 6 & $\begin{array}{l}\text { Chang- } \\
\text { Halpenny } \\
\text { et al }\end{array}$ & 2016 & $\begin{array}{l}\text { retrospective study at one single center } \\
\text { from } 1995 \text { to } 2012\end{array}$ & US & $65(35-84)$ \\
\hline 7 & $\begin{array}{l}\text { Nguyen et } \\
\text { al }\end{array}$ & 2016 & $\begin{array}{l}\text { retrospective cohort study at } 2 \text { academic } \\
\text { cancer centers from } 2000 \text { to } 2014\end{array}$ & Canada & $\begin{array}{l}65(45- \\
96), \text { mean } \\
66.55 \pm 11.1\end{array}$ \\
\hline 8 & $\begin{array}{l}\text { Mahdi et } \\
\text { al }\end{array}$ & 2016 & $\begin{array}{l}\text { retrospective review from SEER from } 2000 \\
\text { to } 2009\end{array}$ & US & $\begin{array}{l}\text { CT: } 68(30- \\
87) \\
\text { CT + RT: } 64 \\
(34-85)\end{array}$ \\
\hline 9 & $\begin{array}{l}\text { Cetinkaya } \\
\text { et al }\end{array}$ & 2017 & $\begin{array}{l}\text { retrospecitve study at one signle center } \\
\text { from } 2008 \text { to } 2014\end{array}$ & Turkey & $\begin{array}{l}\text { mean } 64 \pm \\
9.8(49-84)\end{array}$ \\
\hline 10 & Sari et al & 2017 & $\begin{array}{l}\text { retrospective study from } 8 \text { gynecologic } \\
\text { oncology centers from January } 1997 \text { to } \\
\text { November } 2016\end{array}$ & Turkey & $63(42-84)$ \\
\hline 11 & Hong et al & 2017 & $\begin{array}{l}\text { identified from the National Cancer Data } \\
\text { Base from January, } 1998 \text { to December, } \\
2012\end{array}$ & US & 68 \\
\hline 12 & $\begin{array}{l}\text { Shinde et } \\
\text { al }\end{array}$ & 2018 & $\begin{array}{l}\text { identified from the National Cancer } \\
\text { Database between } 2004 \text { and } 2015\end{array}$ & US & NA \\
\hline 13 & $\begin{array}{l}\text { Armbruster } \\
\text { et al }\end{array}$ & 2019 & $\begin{array}{l}\text { a retrospective review conducted at the } \\
\text { University of Texas MD Andreson from } \\
\text { January } 2010 \text { to April } 2016\end{array}$ & US & $\begin{array}{l}65.1(34- \\
94)\end{array}$ \\
\hline
\end{tabular}




\subsection{Comparison of OS between CT and non-CT groups}

In order to compare OS between patients receiving chemotherapy (CT group) and patients receiving other therapy except chemotherapy (non-CT group), 7 trials from 6 studies (Hsu et al 2014, Chang-Halpenny et al 2016, Nguyen et al 2017, Sari et al 2017, Hong et al 2017, Armbrsuter et al 2019) were included in the pooled analysis. Data extracted from 494 patients receiving CT and 1860 patients receiving non-CT were summarized. Pooled data revealed no difference in OS between the two groups $\left(p=0.48,1^{2}=0 \%\right)$. Consequently, a fixed-effect model was applied to estimate the overall outcomes. The OR of CT versus non-CT was 0.75 (95\% Cl: 0.58-0.96, p = 0.02), indicating a significant higher 5-year OS in CT group when compared to the non-CT group [Figure 1]. When comparing patients receiving CT versus those without any adjuvant therapy, the OR was $0.91(95 \% \mathrm{Cl}: 0.35-2.36, \mathrm{p}=0.85)$, suggesting that OS was not significant between these groups [Supplement Fig. 3].

\subsection{Comparison of OS between RT and non-RT groups}

For OS between patients receiving radiotherapy (RT group) and patients receiving other therapy except radiotherapy (non-RT group), 10 trials (Creasman et al 2004, Thomas et al 2007, Rauh-Hain et al 2009, Hsu et al 2014, Ly et al 2014, Chang-Halpenny et al 2016, Nguyen et al 2017, Sari et al 2017, Shinde et al 2018, Armbruster et al 2019) were included in the pooled analysis. Extracted data from 679 patients receiving RT and 1198 patients receiving non-RT were summarized. Importantly, pooled data revealed significant difference between the $O S$ of these two groups $\left(p=0.02, I^{2}=55 \%\right)$. So, a random-effect model was utilized to estimate the overall outcomes. Results revealed that OR of RT versus non-RT was 0.71 (95\% Cl: $0.42-1.19, p=0.19$ ), indicating no significant difference of overall survival between RT and nonRT groups [Figure 2]. Comparing OS for patients receiving RT with those without any adjuvant therapy, the OR was 0.60 (95\% Cl: 0.31-1.18, $\mathrm{p}=0.14$ ) [Supplement Fig. 4].

\subsection{Comparison of OS between patients receiving CT plus RT and those with CT or RT alone}

For OS comparison between patients receiving CT plus RT and those with CT or RT alone, 5 trials (Hsu et al 2014, Chang-Halpenny et al 2016, Sari et al 2017, Mahdi et al 2016, Armburster et al 2019) were included in the pooled analysis, in which 105 patients receiving CT plus RT and 248 receiving CT or RT alone were analyzed. Pooled data revealed significant difference in OS between these two groups $(p=$ $0.70, I^{2}=0 \%$ ). Consequently, a fixed-effect model was applied to estimate the overall outcomes. The OR of CT plus RT versus CT or RT therapy alone was $1.12(95 \% \mathrm{Cl}: 0.63-1.99, p=0.70)$, indicating that the OS of these groups showed no significantly difference [Figure 3]. For comparison of OS between patients receiving CT plus RT and those with no adjuvant therapy, 4 trials (Hsu et al 2014, Chang-Halpenny et al 2016, Sari et al 2017, Armburster et al 2019) were included in the pooled analysis with extracted data from a total of 53 patients receiving CT plus RT and 107 receiving no adjuvant therapy. The OR of CT 
plus RT versus no adjuvant therapy groups was $1.02(95 \% \mathrm{Cl}: 0.44-2.35, \mathrm{p}=0.97)$, indicating that there was no significant difference in OS between these groups using a fixed-effect model for overall outcome estimation [Supplemental Fig. 5].

\subsection{Comparison of PFS between CT and non-CT groups}

In order to compare PFS between patients receiving CT and non-CT, 2 trials (Hsu et al 2014, Nguyen et al 2017) were included in the pooled analysis with 47 patients receiving CT and 140 receiving non-CT. Pooled data revealed no significant difference in PFS between these two groups $\left(p=0.30,1^{2}=7 \%\right)$, and therefore, a fixed-effect model was applied to estimate the PFS outcomes. The OR of CT versus non-CT was 0.44 (95\% Cl: $0.17-1.13, p=0.09)$, indicating that close to being statistically significant difference in PFS between CT and non-CT groups [Supplemental Fig. 6].

\subsection{Comparison of PFS between RT and non-RT groups}

For PFS comparison between patients receiving RT and non-RT, 2 trials (Thomas et al 2007, Hsu et al 2014) were included in the pooled analysis. In particular, extracted data from 58 patients receiving RT and 79 receiving non-RT revealed statistically significant difference of PFS between these two groups $(p=$ $0.0004, I^{2}=92 \%$ ), and therefore, a random-effect model was applied to estimate the overall outcomes. The OR of RT versus non-RT was 1.18 (95\%Cl: $0.06-23.64, p=0.91)$, indicating no significant difference of PFS between patients receiving RT and non-RT groups [Supplemental Fig. 7].

\subsection{Meta-regression and subgroup analyses}

The heterogeneity issue between all included studies was addressed. We performed meta-regression analyses to explain expected heterogeneity in the comparison of OS between patients receiving RT and non-RT, $\left(I^{2}=55 \%\right)$, by testing the effects of factors like sample size (case number $>80$ versus $<80$ ), nationality (Asia versus Europe and US) and publication year (before versus after 2010). Interestingly, the results indicated that difference in nationality contributed significantly to the overall heterogeneity $(Z=$ $0.03, p=0.0172$ ) (Table 2). Therefore, subgroup analyses were performed. Data revealed that analyses on left 9 publications from Europe and US with a total number of 1785 patient indicated no heterogeneity $\left(I^{2}\right.$ $=0 \%)$. The pooled data revealed OR of RT versus non-RT was 0.58 (95\% Cl: $0.44-0.77)$ and 5-year OS in RT group was significantly higher compared to the non-RT group using a fixed-effect model $(p=0.0002)$. Analysis on patients from Asia was not performed due to limited number of publication $(n=1)$ (Table 3$)$. 
Table 2

Meta-regression of factors in patients receiving Radiotherapy and Not-Radiotherapy.

\begin{tabular}{|llllll|}
\hline Heterogeneity factors & Coefficient & SE & Z & P-value & 95\% Cl \\
\cline { 5 - 7 } & & & & & (lower limit, upper limit) \\
\hline No of patients & 0.438 & 0.594 & 1.55 & 0.4853 & $0.38-6.31$ \\
\hline Publication year & 0.571 & 0.6645 & 1.77 & 0.4186 & $0.37-8.52$ \\
\hline Nationality & -3.484 & 1.1216 & 0.03 & 0.0172 & $0.00-0.44$ \\
\hline Abbreviations: SE: standard effect; Cl: confidence interval & & \\
\hline
\end{tabular}

Table 3

Subgroup analysis of factors in patients receiving Radiotherapy and Not-Radiotherapy.

\begin{tabular}{|c|c|c|c|c|c|c|}
\hline \multirow{2}{*}{$\begin{array}{l}\text { Subgroup } \\
\text { factors }\end{array}$} & \multirow[t]{2}{*}{ criteria } & \multirow{2}{*}{$\begin{array}{l}\text { No of } \\
\text { Articles }\end{array}$} & \multirow[t]{2}{*}{$\mathbf{Z}$} & \multirow{2}{*}{$\begin{array}{l}P \\
\text { value }\end{array}$} & \multirow[t]{2}{*}{$12 \%$} & \multirow{2}{*}{$\begin{array}{l}\text { OR } \\
95 \% \mathrm{Cl}\end{array}$} \\
\hline & & & & & & \\
\hline \multirow[t]{2}{*}{ No of patients } & $<80$ & 5 & 1.71 & 0.09 & 0 & $0.57(0.30-1.09)$ \\
\hline & $>80$ & 5 & 0.43 & 0.67 & 76 & $0.84(0.39-1.84)$ \\
\hline \multirow[t]{2}{*}{ pulication year } & $\begin{array}{l}\text { before } \\
2010\end{array}$ & 3 & 1.39 & 0.16 & 0 & $0.56(0.25-1.26)$ \\
\hline & after 2010 & 7 & 0.75 & 0.46 & 68 & $0.77(0.40-1.52)$ \\
\hline \multirow[t]{2}{*}{ Nationality } & Asia & 1 & 3 & 0.003 & $\begin{array}{l}\text { Not } \\
\text { applicable }\end{array}$ & $\begin{array}{l}25.22(3.05- \\
208.33)\end{array}$ \\
\hline & $\begin{array}{l}\text { US + } \\
\text { Europe }\end{array}$ & 9 & 3.77 & 0.0002 & 0 & $0.58(0.44-0.77)$ \\
\hline
\end{tabular}

\subsection{Publication bias}

In CT and non-CT groups, funnel plots formed a very distinctive symmetrical funnel shape with log ORs of the OS. These results implied that no publication bias was detected in the present study (Begg's test, $p$ $=0.07$, Egger's test, $p=0.62$ ) (Supplemental Fig. 8). In RT and non-RT groups, no evidence of publication bias was detected as well (Begg's test, $p=0.48$, Egger's test, $p=0.32$ ) (Supplemental Fig. 9).

\section{Discussion}

UCCC, a relatively rare cancer of the endometrium, exhibits poor patients' prognosis even at early stage of the disease such as stage I-II. CT or RT has been applied as the adjuvant treatment after surgery to 
improve prognosis. However, it remains controversial of the effectiveness of CT or RT as the adjuvant therapy for early stage UCCC due to small number of cases reported in a limited few studies. Our study is the first meta-analysis, which aims to evaluate the effectiveness of adjuvant CT or RT on survival outcomes in stage I-II UCCC.

Our meta-analysis results have supported the notion that CT is beneficial for early stage, i.e. stage I-II UCCC. In particular, we found that patients receiving CT showed a significant higher 5 year-OS rate compared to those receiving non-CT ( $p=0.007)$. This result was evidenced based on the pooled extracted data from 494 CT and 1860 non-CT patients without internal difference from a total of 7 trials $(p=0.48$, $\mathrm{I}^{2}=0 \%$ ). Interestingly, in the study of Hsu et al., 2 cases of death were reported from a total of 30 cases receiving adjuvant $\mathrm{CT}$, while 9 death cases found from the 62 cases without receiving CT. According to the authors of this study, patients that did not receive adjuvant treatment tended to have lower risk of recurrence as evidenced by smaller tumor sizes and less myometrial invasion (6). In a study that consisted the largest study cohort, Hong et al. analyzed the data from the National Cancer Data Base (NCDB) and found that women undergoing hysterectomy, lymph node dissection (LND) and CT had the highest 5-year OS, followed by those with hysterectomy and LND without CT (13). Taken together, these results supported the use of CT in the treatment of early stage UCCC.

In the latest Randomized Trial of Radiation Therapy With or Without Chemotherapy for Endometrial Cancer (PORTEC-3), patients with serous or clear-cell cancers had an improvement in failure-free survival with the addition of CT, similar to those with endometriod endometrial cancer (18). In addition, the Society of Gynecologic Oncology (SGO) has recommended the use of adjuvant treatment with CT for stage I-II UCCC patients (19). Together, all data has again confirmed the effectiveness of adjuvant CT in improving OS of the UCCC patients.

On the other hand, adjuvant RT has been applied for the treatment of early stage UCCC, a rationale inferred from the outcome data for women with uterine serous carcinoma and grade III endometrioid carcinoma (20). Application of adjuvant RT in stage I-II patients remains as a controversial topic due to mixed patients' outcome obtained from different studies. Unlike papillary serous tumors, clear-cell carcinoma does not seem to have high propensity for abdomen. So, outcome data from certain trial opposed the routine use of whole-abdominal RT in patients (21). Consistent to these observation, our analyses revealed that OR of RT vs non-RT groups was $0.71(p=0.19)$, implying that the OS was not significantly different between the RT and non-RT groups. Furthermore, Hsu et al. claimed that postoperative adjuvant RT was associated with poorer 5-year recurrence-free interval when compared to CT. Moreover, Chang-Halpenny et al. discovered poorer OS in patients treated with RT, by which the authors believed were due to the inclusion of a great proportion of patients with high-stage disease. Lastly, Hong et al. reported that women undergoing both hysterectomy and LND did not show improved survival rate with either brachytherapy or external beam RT. Taken together, these results have led to the non-favorable recommendation of RT in early-stage UCCC patients by some of the gynecologic oncologists. 
Interestingly, our meta-regression analyses have identified nationality as the source of heterogeneity in the disparity of patients' treatment outcome. After excluding the study of Hsu et al. from analysis, we observed that $\mathrm{I}^{2}$ had reduced to $19 \%$ from $55 \%$ while the $\mathrm{p}$ value had changed to 0.002 (OR: $0.60,95 \% \mathrm{Cl}$ : $0.44-0.83$ ), indicating the superiority of RT in the corresponding US and Europe patients. Consistently, in the PORTEC-3 clinical trial, which involved collaborative efforts of multicenter worldwide, no difference in OS was observed between 29 UCCC patients receiving CT and 33 receiving RT, indicating that both CT and RT could yield favorable prognosis in patients (18). In addition, Desteli et al. also recommended vaginal brachytherapy for the treatment of UCCC (22). Lastly, Kim et al. conducted a large retrospective analysis of 451 UCCC and 882 UPSC (uterine papillary serous carcinoma) patients from the SEER database and found that the 5-year OS for RT and non-RT patients at stage IB were $76 \%$ and $66 \%$ respectively $(p=0.006)$ whereas the 5 -year OS for RT and non-RT patients at stage IC were $60.7 \%$ and $33.9 \%$ respectively $(p=0.001)(23)$. In short, all the evidences thus far have suggested adjuvant RT as a favorable treatment option for improving the survival of patients.

It is interesting to note that no survival improvement between patients receiving CT plus RT and CT or RT alone was observed in our meta-analysis $\left(p=0.70,1^{2}=0 \%\right)$. However, we could not exclude the possibility that the negative results might be due to limited available data, i.e. 353 patients from 5 individual studies. Notably, some studies have casted doubts on the efficacy of combinatorial treatment involving both CT and RT. In particular, Mahdi et al. found no statistical difference in OS between CT plus RT and CT only groups in stage I-II UCCC patients (5-year OS is $65 \%$ versus $67 \%, p=0.69$ ). In one GOG study, which involved retrospective analysis of 13 patients with stage I-II UCCC treated with whole abdominal radiotherapy, the 5-year PFS was 54\%. Interestingly, treatment failures were often observed in patients receiving RT. Therefore, the authors concluded that adjuvant CT was necessary for the patients with radio-resistant cancers (24).

The prevalence of usage of CT and RT in UCCC is increasing in the recent years though controversies remain. With limited number of cases, Vogel et al. found a survival benefit in patients with stage IB to II disease with any form of adjuvant treatments including RT, CT or both (25). From the periods of 1998 to 2001 and 2005 to 2006 , Xu et al. also found a declining use of observation (43.4 versus $41.7 \%$ ) and RT alone $(42.2$ versus $27.1 \%)$ for stage I-II UCCC ( $p<0.001)(26)$. In comparison, the increased use of CT and RT throughout the years was noted. Consequently, we have focused on the studies published from 2004 to 2019, with most of the studies published between 2016 and 2019, to ensure that our analyses capture the timely and representative CT and RT emerging era.

Nevertheless, our study consists of several limitations. Firstly, we have only included 13 papers for analyses due to our strict inclusion criteria. In particular, certain studies that only had limited number of UCCC cases were omitted from our analyses. Secondly, we only selected OS and PFS as the indexes for prognostic analysis as most of the studies did not have survival data such as DFS (Disease-Free Survival), TTP (Time to Progression) or ORR (Objective Response Rate). Lastly, the design of each individual study, such as the CT regimens and types of RT, was different, which might influence the final reporting of our meta-analysis. 
In conclusion, as the first meta-analysis with nearly 4000 patients, our results support the administration of RT and CT for stage I-II UCCC patients. However, it remains to be elucidated how the treatments should be integrated into the adjuvant setting. Therefore, more prospective and randomized clinical trials with larger sampling size should be performed in the future.

\section{Abbreviations}

CT:chemotherapy; EBRT:external beam radiation therapy; GOG:Gynecologic Oncology Group; RT:radiotherapy; OS:overall survival; PFS:progression free survival; UCCC:Uterine Clear Cell Carcinoma; UPSC:uterine papillary serous carcinoma; OR:odds ratio; Cl:confidence interval

\section{Declarations}

\section{Ethics approval and consent to participate}

Not applicable.

\section{Consent for publication}

Not applicable.

\section{Availability of data and materials}

Not applicable.

\section{Competing Interests}

All authors declare no conflicts of interest.

\section{Funding}

This work was supported by the National Natural Science Foundation of China (81802585 to X Yin; 81472426 to W Di), the grants from Shanghai Jiao Tong University School of Medicine (DLY201505 to W Di; YG2016MS51 to X Yin), Shanghai Municipal Commission of Health and Family Planning (2013ZYJB0202 and 15GWZK0701 to W Di), and the grant from Science and Technology Commission of Shanghai Municipality (16140904401 to X Yin).

\section{Author contributions}

Concept and design: J.C. and W.D. Data collection: J.C., Y.Z. and Y.X. Data and statistical analysis: J.C., Y.Z. and Y.X. Data interpretation: J.C., Y.X., and W.D. Drafting and revising the manuscript: J.C., G.Z., C.Z., C.W.C, D.C, Y.Z. and X.Y. Authors read and approved the manuscript

\section{Acknowledgments}


Thanks all support from Department of Obstetrics and Gynecology, Ren Ji Hospital, School of Medicine, Shanghai Jiao Tong University. The authors are grateful to all staffs who contributed to this study.

\section{References}

1. Hamilton CA, Cheung MK, Osann K, Chen L, Teng NN, Longacre TA, et al. Uterine papillary serous and clear cell carcinomas predict for poorer survival compared to grade 3 endometrioid corpus cancers. Br J Cancer 2006;94:642-6.

2. Hasegawa K, Nagao S, Yasuda M, Millan D, Viswanathan AN, Glasspool RM, et al. Gynecologic cancer intergroup (gcig) consensus review for clear cell carcinoma of the uterine corpus and cervix. International Journal of Gynecologic Cancer 2014;24:S90-S5.

3. Qu XM, Velker VM, Leung E, Kwon JS, Elshaikh MA, Kong I, et al. The role of adjuvant therapy in stage ia serous and clear cell uterine cancer: A multi-institutional pooled analysis. Gynecologic Oncology 2018;149:283-90.

4. Bestvina CM, Fleming GF. Chemotherapy for endometrial cancer in adjuvant and advanced disease settings. Oncologist 2016;21:1250-9.

5. Thomas M, Mariani A, Wright JD, Madarek EO, Powell MA, Mutch DG, et al. Surgical management and adjuvant therapy for patients with uterine clear cell carcinoma: A multi-institutional review. Gynecol Oncol 2008;108:293-7.

6. Hsu KF, Chou HH, Huang CY, Fu HC, Chiang AJ, Tsai HW, et al. Prognostic factors and treatment outcomes for patients with surgically staged uterine clear cell carcinoma focusing on the early stage: A taiwanese gynecologic oncology group study. Gynecol Oncol 2014;134:516-22.

7. Chang-Halpenny CN, Natarajan S, Hwang-Graziano JM. Early-stage uterine pure and mixed clear cell carcinoma: Outcomes and recurrence with and without adjuvant therapy. American journal of clinical oncology 2018;41:371-8.

8. Cetinkaya N, Selcuk I, Ozdal B, Meydanli MM, Gungor T. Prognostic factors in endometrial clear cell carcinoma. Arch Gynecol Obstet 2017;295:189-95.

9. Nguyen JM, Bouchard-Fortier G, Bernardini MQ, Atenafu EG, Han G, Vicus D, et al. Uterine clear cell carcinoma: Does adjuvant chemotherapy improve outcomes? International journal of gynecological cancer : official journal of the International Gynecological Cancer Society 2017;27:69-76.

10. Felix AS, Brasky TM, Cohn DE, Mutch DG, Creasman WT, Thaker PH, et al. Endometrial carcinoma recurrence according to race and ethnicity: An nrg oncology/gynecologic oncology group 210 study. Int J Cancer 2018;142:1102-15.

11. Shinde A, Li R, Amini A, Chen YJ, Cristea M, Dellinger T, et al. Improved survival with adjuvant brachytherapy in stage ia endometrial cancer of unfavorable histology. Gynecol Oncol 2018;151:8290.

12. Creasman WT, Kohler MF, Odicino F, Maisonneuve P, Boyle P. Prognosis of papillary serous, clear cell, and grade 3 stage i carcinoma of the endometrium. Gynecol Oncol 2004;95:593-6. 
13. Hong JC, Foote J, Broadwater G, Gaillard S, Havrilesky LJ, Chino JP. Impact of chemotherapy and radiotherapy on management of early stage clear cell and papillary serous carcinoma of the uterus. International journal of gynecological cancer : official journal of the International Gynecological Cancer Society 2017;27:720-9.

14. Mahdi H, Moulton L, Nutter B, Cherian S, Rose P. The impact of combined radiation and chemotherapy on outcome in uterine clear cell carcinoma compared with chemotherapy alone. Clin Oncol (R Coll Radiol) 2016;28:776-82.

15. Armbruster SD, Previs R, Soliman PT, Westin SN, Fellman B, Jhingran A, Fleming ND.

Clinicopathologic features and treatment in patients with early stage uterine clear cell carcinoma: $A$ 16-year experience. Gynecol Oncol 2019;154:328-32.

16. Ly D, Rowley BD, Dodson MK, Soisson PA, Jolles CJ, Gaffney DK, Sause WT. Adjuvant radiation in early stage, unfavorable histology endometrial carcinoma is associated with improved local control and survival. Gynecol Oncol 2014;133:250-5.

17. Rauh-Hain JA, Costaaggini I, Olawaiye AB, Growdon WB, Horowitz NS, del Carmen MG. A comparison of outcome in patients with stage 1 clear cell and grade 3 endometrioid adenocarcinoma of the endometrium with and without adjuvant therapy. European journal of gynaecological oncology 2010;31:284-7.

18. de Boer SM, Powell ME, Mileshkin L, Katsaros D, Bessette P, Haie-Meder C, et al. Adjuvant chemoradiotherapy versus radiotherapy alone for women with high-risk endometrial cancer (portec3): Final results of an international, open-label, multicentre, randomised, phase 3 trial. The Lancet Oncology 2018;19:295-309.

19. Olawaiye $A B$, Boruta DM, 2nd. Management of women with clear cell endometrial cancer: A society of gynecologic oncology (sgo) review. Gynecol Oncol 2009;113:277-83.

20. Xu Y, Hanna RK, Elshaikh MA. Adjuvant therapy of uterine clear cell carcinoma: A review. Arch Gynecol Obstet 2016;293:485-92.

21. Murphy KT, Rotmensch J, Yamada SD, Mundt AJ. Outcome and patterns of failure in pathologic stages i-iv clear-cell carcinoma of the endometrium: Implications for adjuvant radiation therapy. Int $J$ Radiat Oncol Biol Phys 2003;55:1272-6.

22. Desteli GA, Dogan NU, Gursu T, Ayhan A. Adjuvant therapy for stage ia uterine clear cell carcinoma with no myometrial invasion: A critical review of literature. European journal of gynaecological oncology 2016;37:17-21.

23. Kim A, Schreiber D, Rineer J, Choi K, Rotman M. Impact of adjuvant external-beam radiation therapy in early-stage uterine papillary serous and clear cell carcinoma. International Journal of Radiation Oncology*Biology*Physics 2011;81:e639-e44.

24. Sutton G, Axelrod JH, Bundy BN, Roy T, Homesley H, Lee RB, et al. Adjuvant whole abdominal irradiation in clinical stages $\mathrm{i}$ and ii papillary serous or clear cell carcinoma of the endometrium: $\mathrm{A}$ phase ii study of the gynecologic oncology group. Gynecologic Oncology 2006;100:349-54. 
25. Vogel TJ, Knickerbocker A, Shah CA, Schiff MA, Isacson C, Garcia RL, Goff BA. An analysis of current treatment practice in uterine papillary serous and clear cell carcinoma at two high volume cancer centers. Journal of gynecologic oncology 2015;26:25-31.

26. Xu KM, Gill BS, Balasubramani GK, Sukumvanich P, Kelley JL, Beriwal S. Utilization and role of adjuvant radiotherapy and chemotherapy for uterine clear cell carcinoma: A national cancer data base analysis. International journal of gynecological cancer : official journal of the International Gynecological Cancer Society 2016;26:472-82.

\section{Figures}

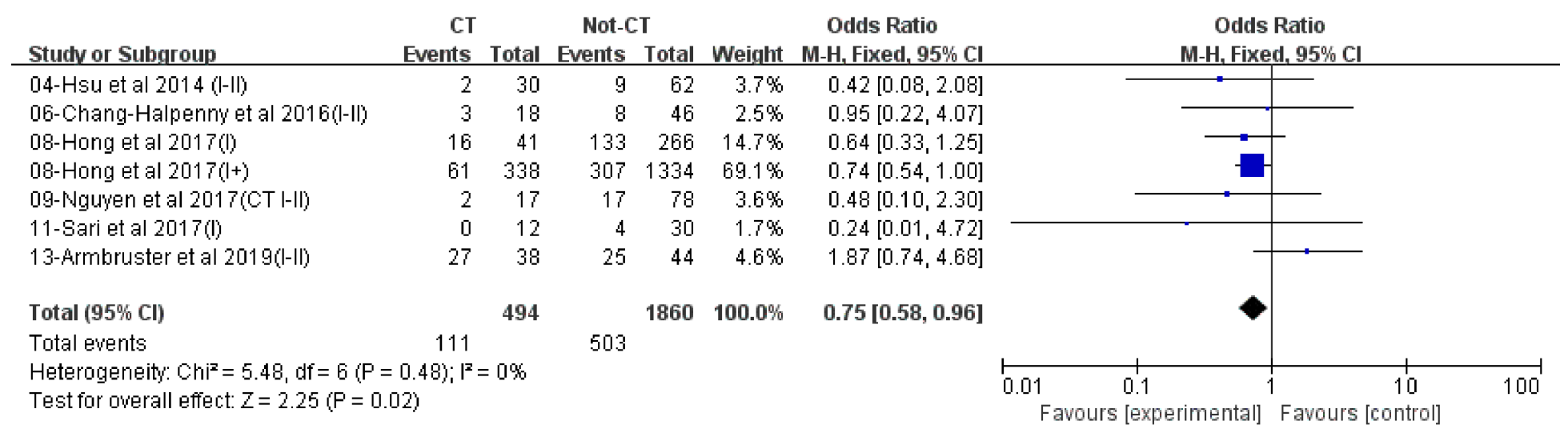

\section{Figure 1}

Pooled studies of overall survival between patients received Chemotherapy (CT) and not-chemotherapy (Not-CT).

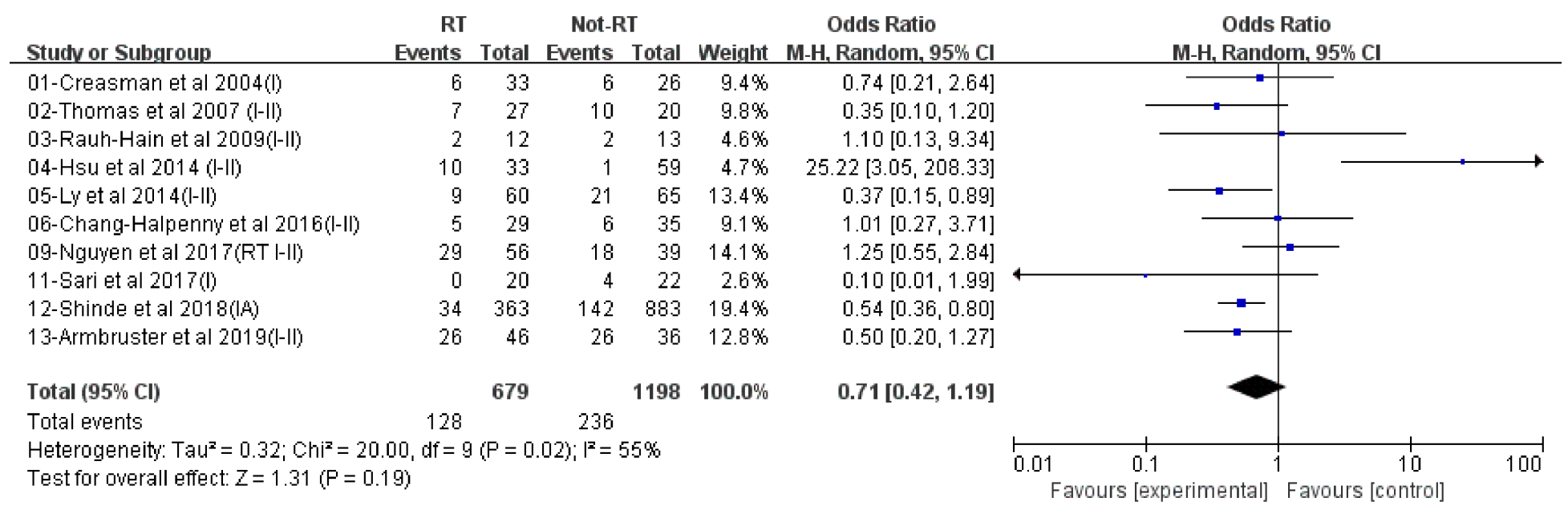

\section{Figure 2}

Pooled studies of overall survival between patients received Radiotherapy (RT) and not-Radiotherapy (Not-RT). 


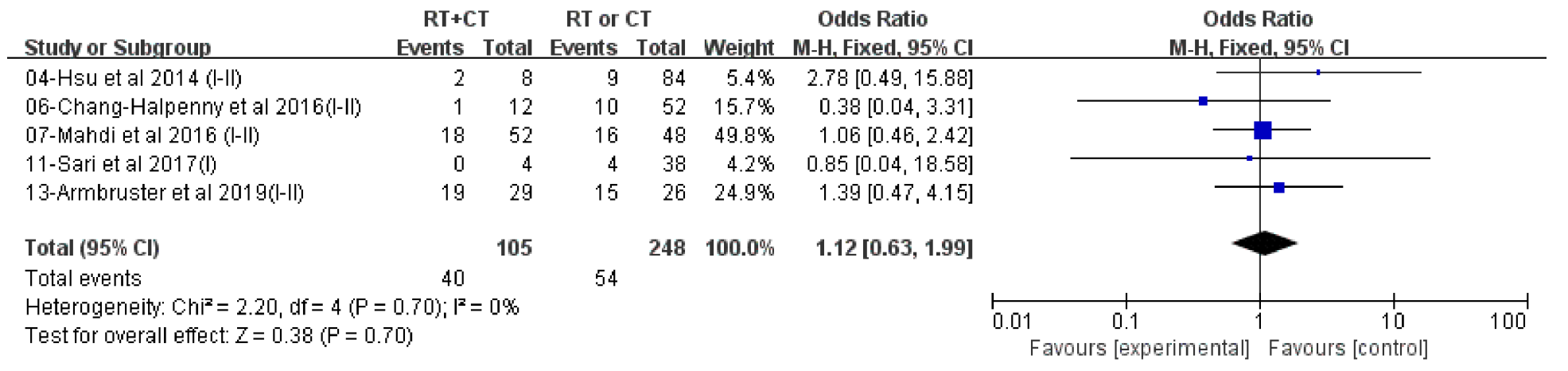

\section{Figure 3}

Pooled studies of overall survival between patients received combinatorial radiotherapy and chemotherapy $(\mathrm{RT}+\mathrm{CT})$ and radiotherapy or radiotherapy (RT or $\mathrm{CT}$ ) alone.

\section{Supplementary Files}

This is a list of supplementary files associated with this preprint. Click to download.

- SupplementaFigures.docx 